\title{
Implication of yoga in noncommunicable diseases
}

\author{
Anil Kumar Pandey, Asim Das ${ }^{1}$ \\ Professor and HOD, Physiology, ESIC Medical College and Hospital, NH-3, NIT, Faridabad, ${ }^{1}$ Professor Physiology, Dean, ESIC Medical College \\ and Hospital, NH-3, NIT, Faridabad, Haryana, India
}

\begin{abstract}
The significance of yoga in health and disease is so extensive and of such a general nature that it has become a necessity for doctors who will be practicing in the current and the coming centuries. A positive attitude and a peaceful mind are conductive to healing and happiness, whatever may be the nature of disease or illness. The evidence generated has made modern medicine accept the love, peace, joy, positive thinking, relaxation, hope, etc., as therapeutic tools. This is how yoga becomes a potent instrument for influencing the mind positively. Based on the above traditional as well as scientific thinking, some of the noncommunicable diseases are mentioned in this article, for which yoga may be used with a favorable effect in modern medicine. The need of the current time is to have an integrated approach toward complete therapy and to utilize yoga therapy in harmonization, cooperation, and collaboration with other systems of medicine such as modern medicine, Ayurveda, and naturopathy. The main aims of the therapeutic implications of yoga should be to increase parasympathetic and decrease sympathetic activities. This enables us to move from a state of ill health and sickness to one of fitness and well-being.
\end{abstract}

Keywords: Non communicable disease, parasympathetic activity, sympathetic activity, yoga

Address for correspondence: Dr. Anil Kumar Pandey, Professor and HOD, Physiology, Registrar Academic, ESIC Medical College and Hospital, NH-3, NIT, Faridabad, Haryana, India.

E-mail: drpandeyak@yahoo.co.in, anikump@esic.in

Received: 11.07.2016, Accepted: 11.07.2016

\section{INTRODUCTION}

It is said that yoga practice will reduce the risk of noncommunicable diseases (NCDs) including heart disease, diabetes, neurological disorder, and respiratory diseases. The significance of yoga in health and disease is so extensive and of such a general nature that it has become a necessity for doctors who will be practicing in the $21^{\text {st }}$ century. ${ }^{[1]} \mathrm{A}$ wide variety of common diseases such as coronary heart disease, hypertension, and diabetes mellitus (DM) are now being documented to a faulty lifestyle. Yoga is probably the best lifestyle ever devised in the history of humanity. ${ }^{[1]}$ It is a simple, devoted, compassionate way and view of life, upon which people

\begin{tabular}{|l|l|}
\hline \multicolumn{2}{|c|}{ Access this article online } \\
\hline Quick Response Code: & Website: \\
\hline & www.joshd.net \\
\cline { 2 - 3 } & \\
\hline
\end{tabular}

across cultures and across countries have stumbled for time to time for centuries. Yoga is finding an increasing approval as a nonpharmacological intervention for the prevention and treatment of diseases. ${ }^{[1]}$ Therefore, all the doctors should be well informed about yoga and how it impacts human body system so that doctors may provide sensible answers to patients about the fundamentals of yoga and its impact on health and diseases..$^{[2,3]} \mathrm{A}$ consultant with a yogic attitude is more likely to transmit to the patient a positive attitude and tranquil substantiation. A positive attitude and a peaceful mind are conductive to healing and happiness, whatever may be the nature of disease or illness. ${ }^{[4]}$

This is an open access article distributed under the terms of the Creative Commons Attribution-NonCommercial-ShareAlike 3.0 License, which allows others to remix, tweak, and build upon the work non-commercially, as long as the author is credited and the new creations are licensed under the identical terms.

For reprints contact: reprints@medknow.com

How to cite this article: Pandey AK, Das A. Implication of yoga in noncommunicable diseases. J Soc Health Diabetes 2017;5:88-93. 
"Yoga can be adept everywhere by people of all age groups, irrespective of their socioeconomic status. It fits in very well with the healthy lifestyle that the WHO has been strongly advocating for throughout the life cycle - from childhood to healthy aging. The United Nation's pronouncement to observe June 21 as the International Yoga Day is a gratitude of this ancient Indian practice which has become global. The Yoga Day will rightly put the spotlight on physical exercise, much needed in today's world when sedentary lifestyle is becoming a leading cause of illness." Emphasizing that the Indian subcontinent had a long history and rich tradition in conventional medicines and practices that contribute to health and wellness of the people, we can say that yoga was one of the finest traditional therapeutic systems in the ancient India. ${ }^{[5]}$

"Yoga is believed to offer means for the actualization of human potential to perfection through its three-dimensional approach to health - physical, mental, and spiritual. Yoga is very much relevant even today - as it is both a physical activity and an effective way of managing stress," and the world is fortunate that such conventional medical practices have survive over the centuries. ${ }^{[5]}$ Till few years back, yoga was considered an adjunct therapy in modern medicine. However, during the last decade, yoga has got incorporated in modern medicine. ${ }^{[5]}$ The diseases of modern civilization such as obesity, hypertension, DM, and coronary artery disease are rooted due to faulty lifestyle. This is a stimulus to search for a healthy lifestyle. Yoga is one of the best lifestyles ever devised by human beings. ${ }^{[6]}$ Psychological stress has a major impact on the diseases related to modern civilization. This is another stimulus to search for strategies for overcoming stress. ${ }^{[6]}$ Yoga provides a new way of looking at life. Stress, anger, hostility, relaxation, peace, love, emotion, and intimacy are difficult to measure, but it provides a solid scientific foundation of mind-body relationship and emergence of psychoneuroimmunology. ${ }^{[7]}$ All these cannot be measured, but their effect on body system can be quantified by measuring certain biomarkers such as cytokine levels or measurement of natural killer cells. Science demands quantifiable evidence. Providing evidence for the effects of emotions on biological features may prove to be a great relevance to the health and disease. ${ }^{[8]}$ The evidence generated has made modern medicine accept the love, peace, joy, positive thinking, relaxation, hope, etc., as therapeutic tools. ${ }^{[9]}$ This is how yoga becomes a potent instrument for influencing the mind positively. ${ }^{[9]}$ Based on the above traditional as well as scientific thinking, below are some of the NCDs, for which yoga may be used with a favorable effect in modern medicine.

\section{YOGA IN OBESITY AND CARDIOVASCULAR DISEASE}

Obesity is a state of mild or low-grade inflammation, ${ }^{[10]}$ which may later culminate in a chronic disorder if remains untreated. A number of inflammatory mediators have been shown to be released by adipose tissue, which acts as an endocrine organ with autocrine regulation. ${ }^{[1]}$ Several studies suggest that inflammation contributes to the causation and progression of cardiovascular disease (CVD). ${ }^{[12,13]}$ Further, inflammatory mediators may trigger rupture of the atherosclerotic plaque which may result in coronary thrombosis and ischemia [Figure 1]. ${ }^{[14]}$ In spite of the considerable improvement in therapeutic modalities in CVD, an effective treatment leftover a challenge. The treatment modalities for weight reduction in the management of patients with CVD and those at an augmented risk are paying attention on nutritional interventions, increased physical activity, and pharmacological management. ${ }^{[15,16]}$ It has been stressed that weight reduction is the main contributor for the correction of deranged lipid profile, ${ }^{[17]}$ especially by reduction in abdominal fat. ${ }^{[18]}$ Recent studies have shown that lifestyle intervention is a promising option in patients with CVD as well as those at an increased risk of CVD. ${ }^{[19]}$ Therefore, lifestyle modifications aiming at weight reduction by physical activity, dietary changes, yogic exercises including breathing exercises, and stress relaxation have a very specific role in the management as well as in the prevention of cardiac diseases. ${ }^{[2]}$ Yoga combines a healthy lifestyle with mental peace, and a

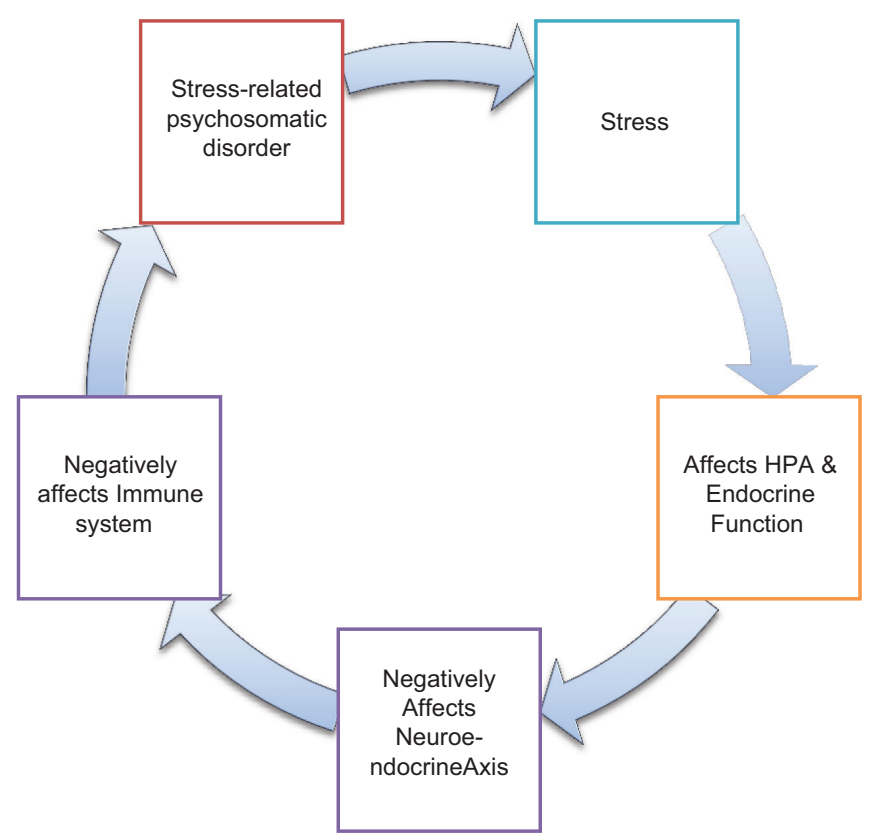

Figure 1: Schematic diagram showing physiological basis of stress and stress-related disorders due to abnormal psycho-neuro-immuno-endocrine system, HPA: Hypothalamic-pituitary-adrenal axis 
modification in lifestyle and calming practices is shown to improve the clinical profile of patients with various pathologies. ${ }^{[8,9]}$ Routine practice of breathing exercise and meditation in healthy individuals led to an improved cardiovascular metabolic status [Figure 1], ${ }^{[1,22]}$ even by a short-term yoga-based routine intervention. ${ }^{[23]}$ Notably, even short-term yoga-based broad lifestyle intervention led to a remarkable reduction in blood pressure (BP), body mass index, and blood glucose with a clinically significant improvement in lipid profile. ${ }^{[24]}$ A similar reduction in weight was observed in another study that included an 8 -week of yoga training that resulted in an improvement in body composition and total cholesterol levels in obese adolescent boys. ${ }^{[25]}$ Long-term changes in lifestyle involving yogic exercises, stress reduction techniques, and fat-free vegetarian diet led to angiographically demonstrable reduction in coronary stenosis. ${ }^{[26,27]}$ Another study showed that Surya namaskar (a yoga posture) resulted in an improved cardio-respiratory fitness. ${ }^{[28]}$ Similarly, a yoga-based lifestyle intervention resulted in a reduction in all lipid profile parameters except high-density lipoprotein. The effect started from 4 weeks and lasted for 14 weeks. ${ }^{[2]}$ All these results indicate that a yogic lifestyle interference may have an effect on some adaptable risk factors, which could make clear the protective and therapeutic valuable impact of yoga in CVD. Overall, lifestyle intervention can transform the evolution of the CVD.

\section{DIABETES MELLITUS}

Abnormal increase in sympathetic activity and reduction in parasympathetic activity have been associated with Type 2 DM. Chronic stress, anxiety, and depression have already been implicated in pathogenesis as well as the aftermath of diabetes. Some studies have shown positive effects of yoga intervention on stress and anxiety. ${ }^{[30]}$ Studies and reviews have clearly shown the positive effects of yoga on glycemic control, BP, lipid profile, stress, anxiety, and depression, but have not identified the mechanisms of the action of yoga in Type 2 DM. Previous studies have clearly stated the need to review mechanisms by which yoga helps in diabetes. ${ }^{[31]}$

Yoga practice is directly related to improved insulin sensitivity to glucose signals in Type $2 \mathrm{DM}$. It attenuates the negative relationship between factors causing insulin resistance such as obesity, increased waist circumference, and dyslipidemia. ${ }^{[32]}$ Yoga also improves the sensitivity of beta cells of pancreas to glucose signals. Manjunatha et al. have stated that there is reduction in the brisk release of insulin when glucose level tends to fall whereas there is an increased insulin release when glucose tends to rise in blood. ${ }^{[33]}$ This mechanism gets support from a previous study of Sahay who observed a fall in fasting insulin level when glucose level is at a minimum level. Yoga optimizes insulin secretion as per bodily requirement through its neuro-endocrinal effects and thereby bringing about normalcy in the insulin/glucose ratio, which is suggestive of better peripheral utilization of insulin and reduced insulin resistance. ${ }^{[34]}$

Yoga has been widely recommended for diabetes. A study by Sahay et al. deliberately dissected yoga into small components and studied each separately. ${ }^{[35]}$ Among the alternatives which reduced fasting and postprandial blood glucose were Pranayama, Dhanurasana + Ardha Matsyendrasana, Halasana + Vajrasana, and Naukasana + Bhujangasana. Further analysis revealed that Dhanurasana was the most effective asana for diabetes. A combination of mudra and salabhasana was ineffective, and produced a nonsignificant rise in fasting blood glucose in their study on five participants. This small number of participants and statistically nonsignificant rise in blood glucose make such a conclusion unwarranted. ${ }^{[35]}$

It is not easy to recognize any lone physiologic mechanism of action of yoga in Type $2 \mathrm{DM}$ as the risk factors and etiologies of Type $2 \mathrm{DM}$ are multi-factorial. Similarly, it is not easy to hypothesize any single unidirectional conduit of yoga action in Type 2 DM. Yoga's mechanisms of action in Type $2 \mathrm{DM}$ are integrated and their effect is multi-systemic. The psycho-neuro-endocrine and immune mechanisms of the action of yoga in Type $2 \mathrm{DM}$ symbolize a possible approach to accepting its holistic effects on disease modulation of Type $2 \mathrm{DM}$. This review suggests psycho-neuro-endocrine and immune mechanisms that may be imperative to perceptive yoga's actions on Type 2 DM [Figures 2 and 3].

\section{YOGA AND HYPERTENSION}

Meditation has been shown to reduce systolic BP and diastolic BP of hypertensive patients in several studies. The mechanism underlying the BP-lowering effect is complicated. ${ }^{[36-38]}$ One theory suggests that imbalance in autonomic performance plays a key role in the origin of hypertension ${ }^{[39-41]}$ comparatively over activity of the sympathetic nervous system which ultimately desensitizes cardiopulmonary and arterial baroreceptor reflex and chemoreceptor reflex, leading to a resetting of threshold $\mathrm{BP}$ values at which regulatory signals are triggered. ${ }^{[42]}$ Controlled breathing with prolonged breath cycles may positively alter, i.e., reduces chemoreceptor sensitivity, thereby reducing arterial baroreceptor lethargy and sympathetic outflow. ${ }^{[43]}$ Other potential mechanisms 


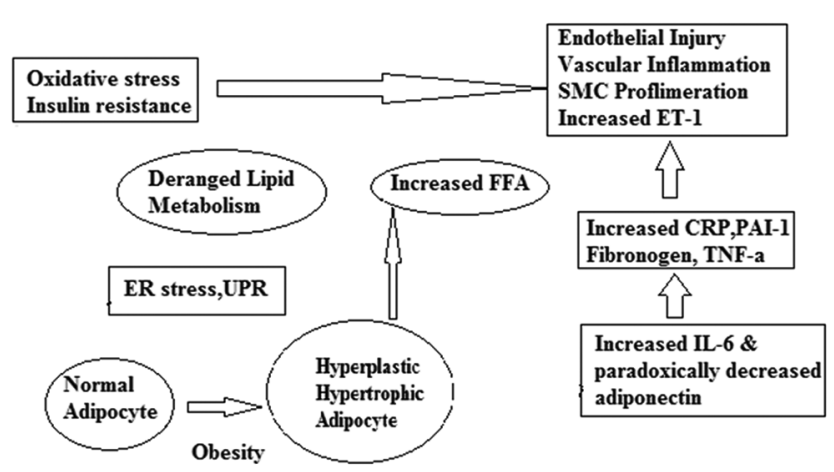

Figure 2: Model for obesity, inflammation, and vascular endothelial

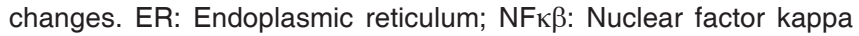
beta; IL-6: Interleukin-6; CRP: C-receptive protein; PAI-1: Plasminogen activator inhibitor-1; TNF- $\alpha$ : Tumor necrosis factor-alpha; FFA: Free fatty acids; SMC: Smooth muscle cells; UPR: Unfolded protein response

involve the fact that amplification of tidal volume activates the Hering-Breuer reflex mediated by pulmonary stretch receptors. ${ }^{[44]}$ This reduces the chemoreflex sensitivity, in turn upregulating baroreflex receptor sensitivity and thereby decreasing arterial BP. It has also been suggested that controlled slow breathing entrains central nervous system nuclei, in which respiratory and cardiovascular system centers cross, thus positively alters the regular sympathetic outflow to the vasculature. ${ }^{[54]}$ Some other studies suggest that the decrease in BP occurs mainly via a decrease in systemic vascular resistance and total arterial compliance ${ }^{[45-47]}$ However, the overall biological mechanism and the integrated neural pathways involved in lowering BP by slow deep breathing have yet to be completely elucidated.

\section{PHYSIOLOGICAL BASIS OF BLOOD PRESSURE LOWERING BY BREATHING EXERCISE}

The mechanism whereby meditation techniques lower BP when it occurs remains unclear. It has been suggested that the mechanisms may lead to reductions in stress and physiological arousal, thereby producing favorable effects on the autonomic nervous system balance ${ }^{[48,49]}$ [Figure 1]. It has been speculated that relaxation techniques may favorably alter autonomic nervous system balance and/or the hypothalamic-pituitary-adrenal (HPA) axis. ${ }^{[0]}$ The precise pathways responsible when relaxation therapies produce a decrease in BP require clarification.

\section{CONTROLLED BREATHING}

Meditation, yoga, and music decrease sympathetic nervous system activity, sensitize arterial and cardiopulmonary baroreceptors, and in so decrease BP lability and increase resting BP. Similarly, slow breathing

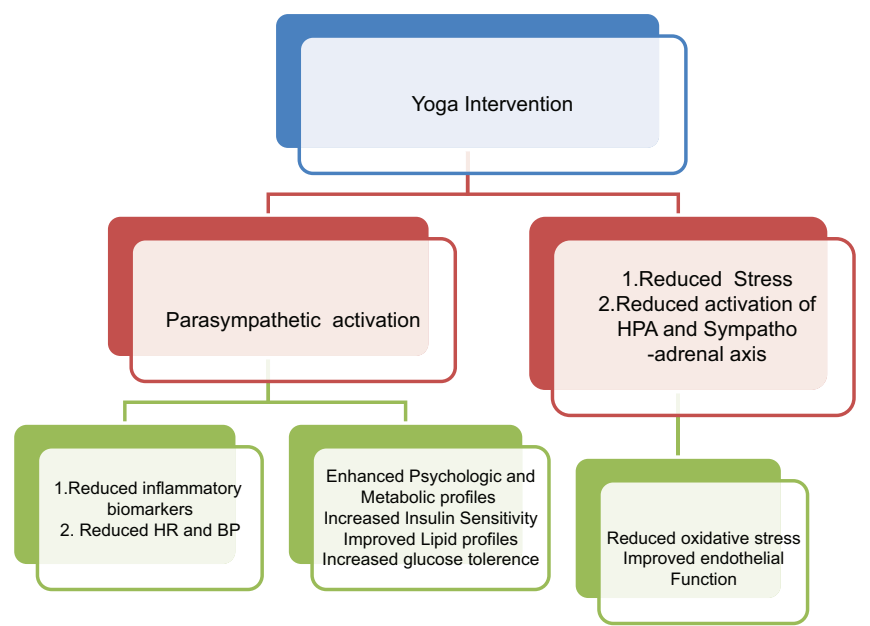

Figure 3: Mechanism of action of yoga through parasympathetic activation and associated anti-stress mechanisms. It reduces perceived stress and hypothalamic-pituitary-adrenal axis activation, thereby improving overall metabolic and psychological profiles, increasing insulin sensitivity, and improving glucose tolerance and lipid metabolism. HPA: Hypothalamic-pituitary-adrenal axis; HR: Heart rate; BP: Blood pressure

( $<8-10$ breath per minute), especially with prolonged expiration, reduced sympathetic nerve activity while increasing parasympathetic activity and reducing BP [Figure 1]..$^{[51,52]}$ The systems require two $12-15 \mathrm{~min}$ sessions daily, endeavoring to achieve at least $45 \mathrm{~min}$ of slow breathing time per week. While there are no known contraindications, this technique requires a fair amount of discipline. The suitable candidates for this therapy might include the prehypertensive or mildly hypertensives, with small BP reductions required; white coat hypertensives where behavioral feedback may minimize the alerting reaction; as a last resort in patients with resistant hypertension and/or those with multiple medication sensitivities/intolerances; and in patients who seek a greater degree of empowerment in managing their hypertension, but still, more persuasive evidence is needed before device-guided breathing can be more generally recommended for BP reduction. ${ }^{[33]}$

\section{ORTHOPEDIC PROBLEMS}

Yogasans have been used for orthopedic problems such as cervical spondylosis and backache, which would benefit from strengthening of specific groups of muscles and also from the improvement of posture. ${ }^{[50]}$ Asans for relaxation have been used for conditions requiring relief from muscle spasm. The favorable effects of yoga in orthopedic problems are not difficult to explain. Asans which strengthen back muscles understandably relieve a backache. Increase in flexibility and decrease in body weight resulting from the asans ameliorate pain not only in the knee joint but also in the other joints. 
PHYSIOLOGICAL BASIS OF ACTION OF YOGA IN NONCOMMUNICABLE DISEASES

We know yoga works, but we do not know how it works. The mind-body relationship is now widely accepted and there is considerable evidence supporting it. ${ }^{[5]}$

It has shown in one study that a set of selected asans return this sensitivity towards normal. Associated with the return of baroreflex sensitivity is a fall in blood pressure towards normal. ${ }^{[56]}$ Stress reduction and the favorable effect of positive emotion on the immune response possibly contribute to the beneficial effect effects of yoga in bronchial asthma patients ${ }^{[5]}$ [Figure 1]. Yogic exercise also benefits asthma by improving pulmonary performance, loss of weight, and physical exercise also improves glucose tolerance, which in turn helps DM. Some dietary modifications add stress reduction, frequently associated with yoga, which may contribute to improvement in glucose tolerance. The same mechanism contributes to the favorable impact on coronary heart disease. ${ }^{[56]}$ According to the theory proposed by Streeter et al., the decreased parasympathetic nervous system and GABAergic activity that underlie stress-related disorders can be corrected by yoga practices resulting in the amelioration of disease symptoms. Heart rate variability testing has a great role to play in our understanding of intrinsic mechanisms behind such potential effects of yoga. Innes et al. had earlier also postulated interconnected pathways by which yoga reduces the risk of CVDs through the mechanisms of parasympathetic activation coupled with decreased reactivity of sympathoadrenal system and HPA axis ${ }^{[56]}$ [Figure 1].

Therefore a shift in autonomic balance toward parasympathetic dominance may explain the decrease in heart rate, fall in BP, and improvement in gastrointestinal function. The increased glucocorticoid secretion in response to an acute stress may explain the better ability to handle the stress. The physical exercise, dietary modification, and stress reduction associated with yogic practices may explain the fall in plasma glucose and improved lipid profile.

\section{FUTURE PROSPECT AND IMPLICATION OF YOGA}

It is now well recognized that stress weakens our immune system. Scientific research in several recent studies has shown that the physiological, psychological, and biochemical impact of yoga are of anti-stress in nature. Mechanisms hypothesized and postulated are the re-establishment of autonomic function balance as well as a progress in healing, regenerative and curative capacity of the individuals.
The main aims of the therapeutic implications of yoga should be to increase parasympathetic and decrease sympathetic activities. It may be further hypothesized that yoga-based practices correct under-activity of the parasympathetic nervous system and gamma-amino butyric acid systems, partly through the stimulation of the vagus nerves, the main peripheral pathway of the parasympathetic nervous system.

This enables us to move from a state of ill health and sickness to the one of fitness and well-being that eventually allows us to move from the lower animal nature to the higher human nature and finally the highest divine nature.

The need of the current time is to have an integrated approach toward complete therapy and to utilize yoga therapy in harmonization, cooperation, and collaboration with other systems of medicine such as modern medicine, Ayurveda, and naturopathy. Advice on diet and lifestyle is very important, irrespective of the mode of therapy that is employed for a particular patient.

\section{Financial support and sponsorship}

Nil.

\section{Conflicts of interest}

There are no conflicts of interest.

\section{REFERENCES}

1. Bijlani RL, Manjunath S. Understanding Medical Physiology: Physiological Effects of Yogic Practices. $4^{\text {th }}$ ed. New Delhi: Jaypee Brothers Medical Publishers; 2014. p. 765-8.

2. Crick F. The Asthonising Hypothesics. The Scientific Search for the Soul. London: Touchstone Books; 1995.

3. Kendel ER. From nerve cells to cognition: The internal cellular representation required for perception and action. In: Kendel ER, Schwartz JH, Jessel TM, editors. Principles of Neural Science. $4^{\text {th }}$ ed. New York: McGraw-Hill; 2000. p. 381-403.

4. Bijlani RL. Is yoga a system of zedicine? New Approaches Med Health 1998;6:27-36.

5. Benson H. Timeless Healing: The Power of Biology of Belief. New York: Scribner; 1996.

6. Madden KS, Felten DL. Experimental basis for neural-immune interactions. Physiol Rev 1995;75:77-106.

7. Glaser R, Kiecolt-Glaser JK. Stress-associated immune modulation: Relevance to viral infections and chronic fatigue syndrome. Am J Med 1998;105:35S-42S.

8. Research contribution of sVYASA (Swami Vivekananda Yoga anusandhan Samasthan) Bangalore: Swami Vivekananda Yoga Prakashan.

9. Look AHEAD Research Group, Pi-Sunyer X, Blackburn G, Brancati FL, Bray GA, Bright R, et al. Reduction in weight and cardiovascular disease risk factors in individuals with type 2 diabetes: One-year results of the look AHEAD trial. Diabetes Care 2007;30:1374-83.

10. Popko K, Gorska E, Stelmaszczyk-Emmel A, Plywaczewski R, Stoklosa A, Gorecka D, et al. Proinflammatory cytokines Il-6 and TNF-a and the development of inflammation in obese subjects. Eur J Med Res 2010;15 Suppl 2:120-2. 
11. Leal Vde O, Mafra D. Adipokines in obesity. Clin Chim Acta 2013;419:87-94.

12. Taube A, Schlich R, Sell H, Eckardt K, Eckel J. Inflammation and metabolic dysfunction: Links to cardiovascular diseases. Am J Physiol Heart Circ Physiol 2012;302:H2148-65.

13. Libby P, Ridker PM, Hansson GK; Leducq Transatlantic Network on Atherothrombosis. Inflammation in atherosclerosis: From pathophysiology to practice. J Am Coll Cardiol 2009;54:2129-38.

14. van der Wal AC, Becker AE, van der Loos CM, Das PK. Site of intimal rupture or erosion of thrombosed coronary atherosclerotic plaques is characterized by an inflammatory process irrespective of the dominant plaque morphology. Circulation 1994;89:36-44.

15. Anderson JW, Kendall CW, Jenkins DJ. Importance of weight management in type 2 diabetes: Review with meta-analysis of clinical studies. J Am Coll Nutr 2003;22:331-9.

16. Aucott L, Rothnie H, McIntyre L, Thapa M, Waweru C, Gray D. Long-term weight loss from lifestyle intervention benefits blood pressure? a systematic review. Hypertension 2009;54:756-62.

17. Hooper L. Primary prevention of CVD: Diet and weight loss. BMJ Clin Evid 2007;2007. pii: 0219.

18. Diaz VA, Player MS, Mainous AG $3^{\text {rd }}$, Carek PJ, Geesey ME. Competing impact of excess weight versus cardiorespiratory fitness on cardiovascular risk. Am J Cardiol 2006;98:1468-71.

19. Larson-Meyer DE, Heilbronn LK, Redman LM, Newcomer BR, Frisard MI, Anton S, et al. Effect of calorie restriction with or without exercise on insulin sensitivity, beta-cell function, fat cell size, and ectopic lipid in overweight subjects. Diabetes Care 2006;29:1337-44.

20. Israili ZH, Hernández-Hernández R, Valasco M. The future of antihypertensive treatment. Am J Ther 2007;14:121-34.

21. Goran MI, Alderete TL. Targeting adipose tissue inflammation to treat the underlying basis of the metabolic complications of obesity. Nestle Nutr Inst Workshop Ser 2012;73:49-60.

22. Bijlani RL. Scientific medicine shows signs of a paradigm shift. New Approaches Med Health 2003;11:28-40.

23. Manchanda SC, Narang R, Reddy KS, Sachdeva U, Prabhakaran D, Dharmanand $\mathrm{S}$, et al. Retardation of coronary atherosclerosis with yoga lifestyle intervention. J Assoc Physicians India 2000;48:687-94.

24. Vyas R, Dikshit N. Effect of meditation on respiratory system, cardiovascular system and lipid profile. Indian J Physiol Pharmacol 2002;46:487-91.

25. Prasad KV, Sunita M, Raju PS, Reddy MV, Sahay BK, Murthy KJ. Impact of pranayama and yoga on lipid profile in normal healthy volunteers. J Exerc Physiol 2006;9:1-6.

26. Yadav RK, Ray RB, Vempati R, Bijlani RL. Effect of a comprehensive yoga-based lifestyle modification program on lipid peroxidation. Indian J Physiol Pharmacol 2005;49:358-62.

27. Ornish D, Brown SE, Scherwitz LW, Billings JH, Armstrong WT, Ports TA, et al. Can lifestyle changes reverse coronary heart disease? The Lifestyle Heart Trial. Lancet 1990;336:129-33.

28. Ornish D, Scherwitz LW, Billings JH, Brown SE, Gould KL, Merritt TA, et al. Intensive lifestyle changes for reversal of coronary heart disease. JAMA 1998;280:2001-7.

29. Sarvottam K, Yadav RK, Mehta N, Mahapatra SC. Effect of short term yoga on resting energy expenditure and lipid profile in overweight/obese subjects: A preliminary study. Indian J Physiol Pharmacol 2010;54:133.

30. Braun TD, Park CL, Conboy LA. Psychological well-being, health behaviors, and weight loss among participants in a residential, Kripalu yoga-based weight loss program. Int J Yoga Therap 2012;22:9-22.

31. Seo DY, Lee S, Figueroa A, Kim HK, Baek YH, Kwak YS, et al. Yoga training improves metabolic parameters in obese boys. Korean J Physiol Pharmacol 2012;16:175-80.

32. Mody BS. Acute effects of Surya Namaskar on the cardiovascular and metabolic system. J Bodyw Mov Ther 2011;15:343-7.

33. Gupta N, Khera S, Vempati RP, Sharma R, Bijlani RL. Effect of yoga based lifestyle intervention on state and trait anxiety. Indian J Physiol Pharmacol 2006;50:41-7.

34. Sengupta P. Health impacts of Yoga and Pranayama: A state-of-the-art review. Int J Prev Med 2012;3:444-58.

35. Zope SA, Zope RA. Sudarshan kriya yoga: Breathing for health. Int J Yoga 2013;6:4-10.

36. Manjunatha S, Vempati RP, Ghosh D, Bijlani RL. An investigation into the acute and long-term effects of selected yogic postures on fasting and postprandial glycemia and insulinemia in healthy young subjects. Indian J Physiol Pharmacol 2005;49:319-24.

37. Sahay BK. Role of yoga in diabetes. J Assoc Physicians India 2007;55:121-6.

38. Resperate for hypertension. Med Lett Drugs Ther 2007;49:55-6.

39. Elliott WJ, Izzo JL Jr. Device-guided breathing to lower blood pressure: Case report and clinical overview. MedGenMed 2006;8:23.

40. Altena MR, Kleefstra N, Logtenberg SJ, Groenier KH, Houweling ST, Bilo HJ. Effect of device-guided breathing exercises on blood pressure in patients with hypertension: A randomized controlled trial. Blood Press 2009;18:273-9.

41. Gavish B. Device-guided breathing in the home setting: Technology, performance and clinical outcomes. Biol Psychol 2010;84:150-6.

42. Pagani M, Somers V, Furlan R, Dell'Orto S, Conway J, Baselli G, et al. Changes in autonomic regulation induced by physical training in mild hypertension. Hypertension 1988;12:600-10.

43. Brook RD, Julius S. Autonomic imbalance, hypertension, and cardiovascular risk. Am J Hypertens 2000;13(6 Pt 2):112S-22S.

44. Radaelli A, Bernardi L, Valle F, Leuzzi S, Salvucci F, Pedrotti L, et al. Cardiovascular autonomic modulation in essential hypertension. Effect of tilting. Hypertension 1994;24:556-63.

45. Oneda B, Ortega KC, Gusmão JL, Araújo TG, Mion D Jr.. Sympathetic nerve activity is decreased during device-guided slow breathing. Hypertens Res 2010;33:708-12.

46. Schelegle ES, Green JF. An overview of the anatomy and physiology of slowly adapting pulmonary stretch receptors. Respir Physiol 2001;125:17-31.

47. Sharma M, Frishman WH, Gandhi K. RESPeRATE: Nonpharmacological treatment of hypertension. Cardiol Rev 2011;19:47-51.

48. Anderson JW, Liu C, Kryscio RJ. Blood pressure response to transcendental meditation: A meta-analysis. Am J Hypertens 2008;21:310-6.

49. Rainforth MV, Schneider RH, Nidich SI, Gaylord-King C, Salerno JW, Anderson JW. Stress reduction programs in patients with elevated blood pressure: A systematic review and meta-analysis. Curr Hypertens Rep 2007;9:520-8

50. Dickinson H, Campbell F, Beyer F, Nicolson DJ, Cook J, Ford G, et al. Relaxation therapies for the management of primary hypertension in adults: A Cochrane review. J Hum Hypertens 2008;22:809-20.

51. Pramanik T, Sharma HO, Mishra S, Mishra A, Prajapati R, Singh S. Immediate effect of slow pace bhastrika pranayama on blood pressure and heart rate. J Altern Complement Med 2009;15:293-5.

52. Nidich SI, Rainforth MV, Haaga DA, Hagelin J, Salerno JW, Travis F, et al. A randomized controlled trial on effects of the transcendental meditation program on blood pressure, psychological distress, and coping in young adults. Am J Hypertens 2009;22:1326-31.

53. Oneda B, Ortega KC, Gusmão JL, Araújo TG, Mion D Jr.. Sympathetic nerve activity is decreased during device-guided slow breathing. Hypertens Res 2010;33:708-12.

54. Selvamurthy W, Sridharan K, Ray US, Tiwary RS, Hegde KS, Radhakrishan U, et al. A new physiological approach to control essential hypertension. Indian J Physiol Pharmacol 1998;42:205-13.

55. Yudkin JS, Kumari M, Humphries SE, Mohamed-Ali V. Inflammation, obesity, stress and coronary heart disease: Is interleukin-6 the link? Atherosclerosis 2000;148:209-14.

56. Innes. Interconnected pathways of yoga to reduce the risk of cardiovascular diseases. J Am Board Fam Pract 2005;s18:491-519. 